\title{
IDONEIDAD DEL PROFESOR DE RELIGIÓN
}

\author{
ON THE QUALIFICATIONS OF TEACHERS OF RELIGION
}

\author{
SENTENCIAS CORTES DE APELACIONES DE SAN MIGUEL Y SUPREMA \\ DE 27 DE NOVIEMBRE DE 2007 Y 17 DE ABRIL DE 2008
}

\section{Jorge Precht Pizarro*}

\begin{abstract}
RESUMEN: Tanto en primera como en segunda instancia fue rechazado el recurso de protección que presentara cierta profesora de religión contra el Vicario para la Educación del Obispado de San Bernardo por habérsele revocado el certificado de idoneidad para impartir las clases. Centrándose el comentario en el considerando octavo de la Sentencia de la Corte de Apelaciones de San Miguel se hace referencia a la corriente moderna de libertad religiosa donde se induce a la colaboración entre Iglesia y Estado; en seguida se desarrolla el significado de una idoneidad necesaria para ejercer como profesor de religión, reforzándose por último el reconocimiento de una legítima independencia y autonomía de la Iglesia Católica y su legislación particular.
\end{abstract}

Palabras clave: Libertad Religiosa, Derecho Canónico, Idoneidad del Profesor, Libertad de Culto, Iglesia Católica.

ABSTRACT: In both instances in trial courts was rejected the "action for protection of basic constitutional rights" (recurso de protección). It was exercised by a teacher of religion classes against the Vicar for Education of San Bernardo based on the revocation of her certification for teaching. Focus on the reasoning number eight of the decision of the San Miguel's Appellate Court, this comment refers to the modern trend of religious freedom thinking that promotes the cooperation between the Roman Catholic Church and the Government. Afterwards it treats what is to be understood by qualifications for being a religious teacher, recognizing finally to the Church a lawful independence and selfgovernment to create its own rules.

Key words: Religious freedom, freedom of worship, qualifications for teaching, Canonical Law, Roman Catholic Church.

En el Boletín Jurídico del Centro de libertad religiosa año III N ${ }^{\circ} 2$ noviembre 2007 se publicó (páginas 18 a 24) la sentencia de la Corte de Apelaciones de San Miguel de 27 de noviembre de 2007, recaída en el recurso de protección presentado por la profesora de religión doña Sandra Cecilia Pavez Pavez en contra del Vicario para la Educación del Obispado de San Bernardo, presbítero don René Aguilera Colinier (rol Nº 238 - 2007).

\footnotetext{
* Licenciado en Ciencias Jurídicas Universidad de Chile, Magíster en Derecho Internacional y Comparado en la Vrije Universiteit van Brussel, y Doctor en Derecho por la Université Catholique de Louvain, Profesor Titular de Derecho Administrativo de la Pontificia Universidad Católica de Chile, correo de contacto: jprecht@uc.cl
} 
En la antedicha sentencia se decidió que el recurso quedaba rechazado respecto de la profesora de religión doña Sandra Pavez Pavez y que era declarado inadmisible respecto del Colegio de Profesores A. G. y del Movimiento de Integración y Liberación Sexual Movilh. Esta sentencia fue dictada por unanimidad.

Con fecha 17 de abril del 2008, la Tercera Sala de la Excma. Corte Suprema (ministros señores don Adalis Oyarzún, don Pedro Pierry y doña Sonia Araneda, y abogados integrantes don Hernán Álvarez y don Domingo Hernández) confirmó la sentencia de la Ilustre Corte de Apelaciones de San Miguel, de 27 de noviembre pasado, y se rechazó la apelación interpuesta en todas sus partes.

La sentencia de la Excma. Corte Suprema señala, por la unanimidad de sus 5 integrantes: "No se reciben alegatos en esta causa, y se confirma la sentencia apelada".

Por ello la argumentación de la Ilma. Corte de San Miguel quedó intacta.

Me parece que a efectos de la libertad religiosa y de los derechos de todas las iglesias (incluida la Iglesia Católica), debe ser destacado el considerando octavo: "Que el tantas veces citado Decreto 924 de Educación dispone claramente que el profesor de Religión (entendiendo por tal el de cualquier credo religioso), debe contar con un certificado de idoneidad otorgado por la autoridad religiosa que corresponda "cuya validez durará mientras esta no se revoque”. Es decir, la propia legislación aplicable en la especie, faculta al órgano religioso correspondiente para que otorgue y revoque la autorización que se ha de conceder de acuerdo con sus particulares principios religiosos, morales y filosóficos, situación que dependerá solo de cada una de ellas no teniendo injerencia alguna ni el Estado ni algún particular puesto que la facultad descansa en el propio credo que tiene la amplia libertad para establecer sus normas y sus principios. Considerarlo de otra manera sería intervenir en los grupos religiosos y no respetar sus propias normas, cuestión que no es precisamente lo que pretende establecer el Decreto en análisis. Subyace en la propia norma citada que quien imparta tal credo en las aulas deberá ajustarse a dichas normas, creencias y dogmas sin que competa a los órganos del Estado inmiscuirse o cuestionarlas".

Como puede observarse, lo argumentado por la Corte de Apelaciones de San Miguel es una consecuencia de lo que los Soberanos Pontífices han denominado "una sana laicidad", es decir una independencia entre las iglesias y el Estado, independencia que no excluye la colaboración entre ambos poderes, no solo en materias de interés común, sino sobre todo en la construcción del bien común temporal, uno de cuyos pilares es la educación.

La sentencia en este plano se adentra en la corriente moderna sobre libertad religiosa, superando el debate estrecho de "separación entre las iglesias y el Estado", que mira solo los aspectos negativos y que no induce a la colaboración entre ambos poderes. Por lo demás, el Estado -en un Estado Social y Democrático de Derecho- tiene el deber de promover la libertad religiosa y de remover los obstáculos que se oponen a su libre ejercicio y ello para todas las creencias que no se opongan a la moral, las buenas costumbres y el orden público.

Ahora bien, ¿qué significa la idoneidad necesaria para ejercer como profesor de Religión de la que habla el artículo $9^{\circ}$ del Decreto 904?

A mi juicio la "idoneidad" implica tres aspectos: idoneidad profesional; idoneidad doctrinal e idoneidad moral. 
En primer lugar, la idoneidad profesional significa contar con las herramientas pedagógicas necesarias para enseñar (en general) y para enseñar Religión (en particular). Lo ideal sería que pedagogos, licenciados en educación parvularia, básica o media, hicieran una especialización en Religión. Pero cómo ello no es posible por el momento, es imprescindible lograr que todos los enseñantes católicos cuenten con una especialización en Religión, en un establecimiento de educación superior católica o reconocida por esta.

En segundo lugar, la idoneidad doctrinal. Es evidente que la autoridad religiosa que emita un certificado de idoneidad debe asegurarse que la enseñanza impartida corresponda a la doctrina oficial de la Religión. En efecto, tiene que haber una perfecta adecuación entre la educación religiosa "que esté de acuerdo con las propias convicciones de la persona que reciba tal instrucción” y la enseñanza que se otorga. Sería una especie de fraude o de abuso de confianza el que, declarándose el alumno o sus padres católicos o de otra religión, recibiera el pupilo una enseñanza ajena a la misma, no solo herética o heterodoxa, sino también aquella creada por la libre imaginación del docente.

$\mathrm{Y}$ en tercer lugar, la idoneidad moral ya que de toda creencia religiosa (e incluso de una creencia no religiosa) se desprende un comportamiento moral derivado de esa creencia. El docente debe ser coherente con la conducta exigida a los miembros de su Religión. Recuérdese que la ley 19.638 dice que la libertad religiosa, significa para toda persona: "recibir o impartir enseñanza religiosa... elegir... la educación religiosa y moral que esté de acuerdo con sus propias convicciones".

La autoridad religiosa debe velar no solo porque se enseñe una doctrina recta, sino porque el docente sea consecuente, a lo menos, en los puntos más cruciales de esa moral. El docente de Religión no solo enseña con su palabra, sino ante todo con su ejemplo. Lo contrario movería a escándalo.

Pero la segunda parte del considerando octavo de la sentencia confirmada es de suma importancia para la Iglesia Católica ya que afirma lo siguiente: "El Decreto 924 debe relacionarse a su vez, con las normas contenidas en los artículos 803, 804, 805 y 806 del Código de Derecho Canónico en cuanto este último cuerpo legal consagra la facultad de la Iglesia Católica y sus autoridades para fijar las directrices necesarias en el ámbito de la difusión de la fe católica, tanto en cuanto a su contenido como a la idoneidad de las personas encargadas de la enseñanza de la doctrina de la Iglesia”.

En efecto, este razonamiento refuerza de modo implícito dos artículos clave para la legítima independencia y autonomía de la Iglesia Católica, a saber el artículo 547, inciso segundo del Código Civil y el artículo 20 de la Ley de iglesias y entidades religiosas $\mathrm{N}^{\circ} 19.638$.

El artículo 547, inciso segundo del Código Civil dice lo siguiente: “Tampoco se extienden las disposiciones de este título a las corporaciones o fundaciones de derecho público, como la nación, el fisco, las municipalidades, las iglesias, las comunidades religiosas y los establecimientos que se costean con fondos del Erario; estas corporaciones y fundaciones se rigen por las leyes y reglamentos especiales".

La jurisprudencia ha aplicado siempre esta norma solo a la Iglesia Católica, en cuyo caso ha entendido que al hablar de "leyes y reglamentos especiales" se refiere el Código Civil al Derecho Canónico. 
Por ello es particularmente pertinente que se hable, en el considerando noveno de la sentencia, de "cuerpo legal" para referirse al Código de Derecho Canónico al que reenvía el Código Civil.

Pero también implícitamente se refuerza el artículo 20 de la ley 19.638. En efecto, tal artículo -en el caso de la Iglesia Católica- garantiza que ella se rige por el ordenamiento (estatal) vigente a la fecha de publicación de la Ley de iglesias. Esta norma implica que el Decreto 924 es parte del ordenamiento y por tanto está vigente para las iglesias allí mencionadas dentro de las cuales está la Iglesia Católica. La ley 19.638 fue publicada el 10 de octubre de 1999.

Pero el artículo 20 dice que se reconoce que (la Iglesia Católica) se rige además por "el régimen jurídico que le es propio", esto es por el Derecho Canónico y ello "sine die".

Por lo tanto, las normas del Derecho Canónico y del derecho estatal mencionadas son aplicables al caso por cuanto el artículo 20 (de la ley No 19.638) dice a la letra: "El Estado reconoce el ordenamiento, la personalidad jurídica, sea esta de derecho público o de derecho privado, y la plena capacidad de goce y de ejercicio de las iglesias, confesiones e instituciones religiosas que los tengan a la fecha de publicación de esta ley, entidades que mantendrán el régimen jurídico que les es propio, sin que ello sea causa de trato desigual entre dichas entidades, y las que se constituyan en conformidad a esa ley".

El ordenamiento, significa el derecho estatal aplicable a las iglesias y entidades religiosas que tuvieren a la fecha de la entrada en vigencia de esta ley, personalidad jurídica sea de derecho público o de derecho privado. Se aplica tal ordenamiento íntegramente. Esa norma contiene tal redacción a fin de que no se entienda que la ley 19.638 afecta el patrimonio jurídico ya adquirido de las iglesias. En consecuencia, todas las iglesias que tenían derecho a impartir enseñanza religiosa conforme al Decreto Supremo 924/1983 (de Educación) mantienen incólumes sus facultades y tienen el derecho a que le sean aplicables sus normas.

Es evidente que el Estado no puede renunciar a su potestad legislativa o reglamentaria hacia el futuro, por ello el ordenamiento es garantizado "hasta la fecha de publicación de la presente ley", por lo cual hacia el futuro pueden darse nuevas normas. Sin embargo, esas nuevas normas serán siempre "ad maiorem", para incrementar el patrimonio jurídico ya adquirido y nunca para reducirlo o constituir limitaciones o trabas a su libre ejercicio. Lo contrario sería contradictorio con los artículos 19 No 23; 19 No 24 y 19 No 26 de la Constitución y también con la letra del artículo 20 de la ley 19. 638.

El sentido y el espíritu de esta ley complementaria sobre libertad religiosa es cartesianamente claro: se trata de crear un ámbito de "suma positiva", esto es que todos ganen con la ley 19.638 y nadie pierda o se sienta amenazado en sus derechos y expectativas legítimas.

Por ende, la mención de los artículos 803, 804, 805 y 806 del Código de Derecho Canónico citados en la sentencia lleva consigo el robustecimiento de la base jurídica estatal en que se apoyan.

En síntesis, no solo nos encontramos ante un triunfo jurídico del Obispado de San Bernardo, sino a la vez y más profundamente se ha obtenido un nuevo reconocimiento de la peculiaridad jurídica de la Iglesia Católica, efectuado no solo como otrora por el Poder Legislativo sino esta vez por el Poder Judicial en sentencia unánime de una Corte de Apelaciones confirmada por la Corte Suprema. 